\title{
Palynological prepara- tion techniques, a new Macerationtank-method and other modifications
}

By Niels Erik Poulsen,

Lasse Gudmundsson, Jens Morten

Hansen and Yvonne Husfeldt

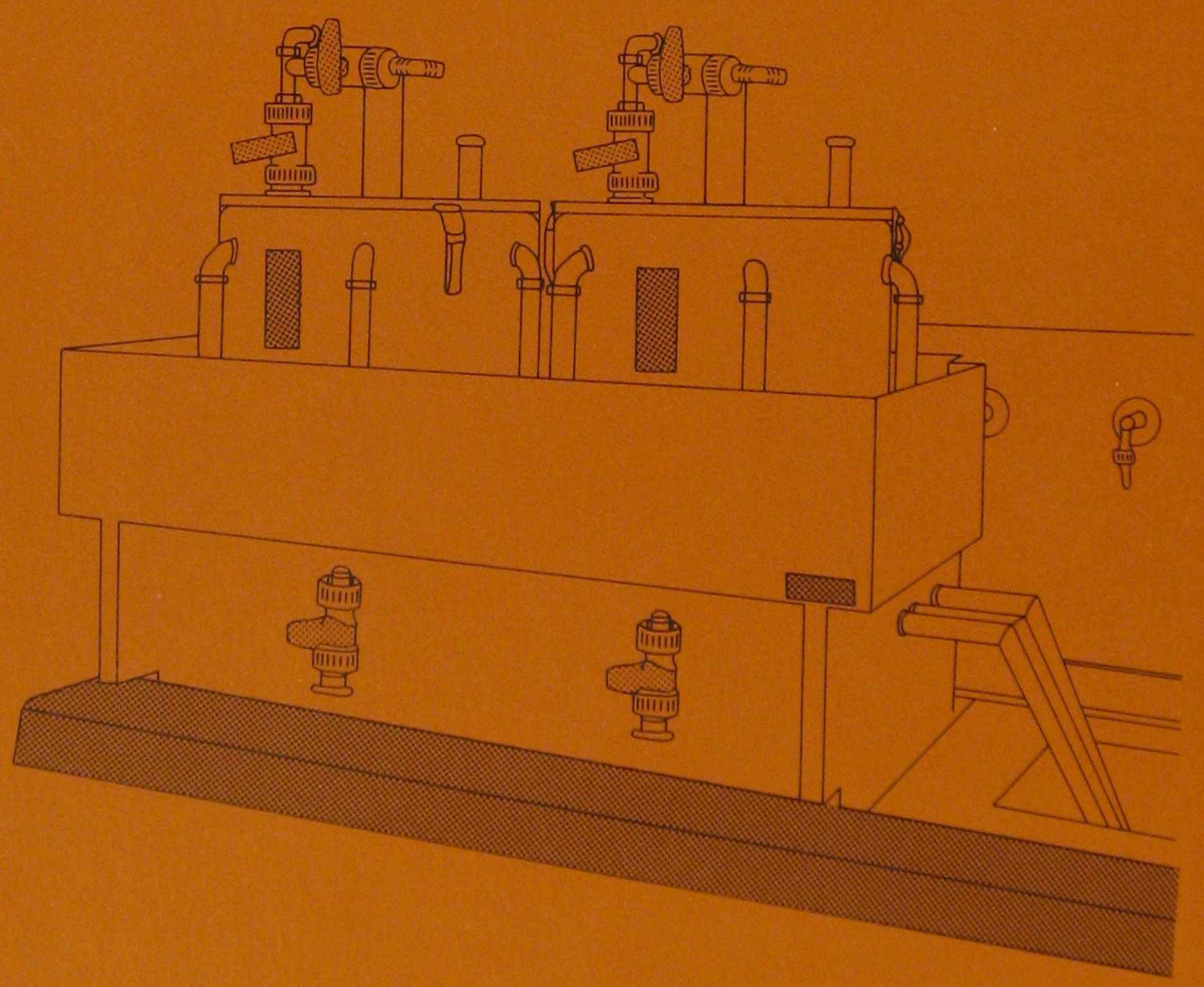




\section{Palynological prepara- tion techniques, a new Macerationtank-method and other modifications}

By Niels Erik Poulsen, Lasse Gudmundsson, Jens Morten Hansen and Yvonne Husfeldt

November 1990

DGU series C. no. 10

ISBN 87-88640-57-4

ISSN 0900-6362 
Keywords:

Palynology, preparation, hydrofluoric acid, maceration, washing machine.

DGU series $\mathrm{C}$ no. 10

ISBN $87-88640-57-4$

ISSN 0900-6362

Printed in 750 copies

Printed at DGU

Sats Latex

DGU 1990-06-20

Manuscript received 20/12 1989

Niels E. Poulsen et al.

Geological Survey of Denmark

Thoravej 8

DK-2400 Copenhagen NV

Editor: Peter Frykman

(C) Geological Survey of Denmark

Thoravej 8, DK-2400 Copenhagen NV 


\section{Contents}

$\begin{array}{ll}\text { Abstract } & 4\end{array}$

Introduction $\quad 5$

Preparation $\quad 7$

Removal of carbonates, the macerationtank-method . . . . . . . . 7

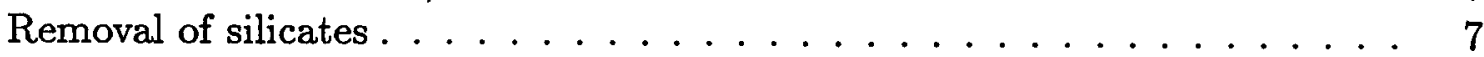

Concentration of palynomorphs . . . . . . . . . . . . 8

Heavy-liquid separation: . . . . . . . . . . . . 8

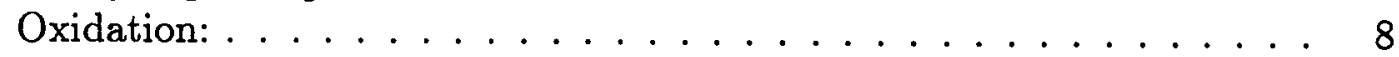

Modified ethanol-water separation: .............. 9

Modified swirling: . . . . . . . . . . . . . . . . . 9

Ultrasonic treatment: . . . . . . . . . . . . . . . . . . 9

Filtration: ....................... 10

Mounting medium for slides: ............... 10

Discussion of the method and tests 11

Rock types ......................... 11

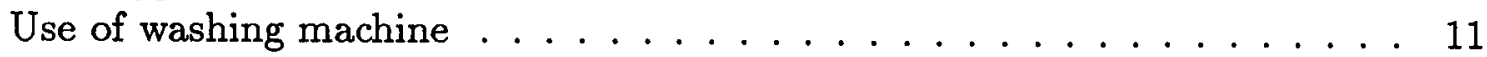

Sources of contamination .................... 12

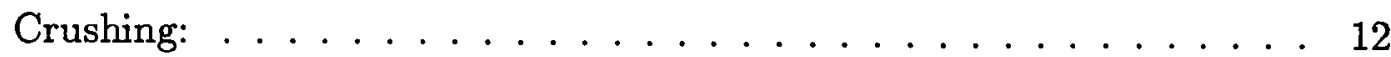

Holes in the filter cloth: ................. 12

$\begin{array}{ll}\text { Conclusion } & 15\end{array}$

$\begin{array}{ll}\text { Description of the macerationtank } & 17\end{array}$

$\begin{array}{ll}\text { Acknowledgements } & 21\end{array}$

References $\quad 23$ 


\section{Abstract}

A safe technique useful in the preparation of spores, pollen, dinoflagellate cysts, acritarchs and other acid-insoluble microfossils is described. The technique utilizes a macerationtank for hydrofluoric acid treatment of palynological samples. The hydrofluoric acid is conducted to and from the macerationtank along tubing. Tests of the method are discussed and the macerationtank is described. Some techniques in subsequent preparation are mentioned. These include heavy-liquid separation, oxidation, ethanol water separation (modified), swirling (modified), ultrasonic treatment, filtration. 


\section{Introduction}

The new palynological preparation technique described was developed at the Geological Survey of Denmark for extracting dinoflagellate cysts, spores, pollen and other microfossils such as acritarchs, Botryococcus, etc. The macerationtank method was developed in order to facilitate the safe handling of hydrofluoric acid.

The technique was developed by L. Gudmundsson, J.M. Hansen and E. Vogensen and presented by L. Gudmundsson at the Nordic Palynological Meeting, which was held at the Geological Survey of Denmark in 1984. The method was published by Gudmundsson (1985).

Later the method and the macerationtank have been further tested and improved by Y. Husfeldt and N.E. Poulsen. The method is now well developed and is as good as conventional methods.

The macerationtank-method is not a rapid method useful for urgent samples, but since samples are handled in groups, the average time spent per sample is about the same as for conventional methods. For larger samples (100-600 grams), the method has proved to be faster.

The principle of the macerationtank-method is that the dangerous hydrofluoric acid is carried to the macerationtank along tubing using connected vessels. The samples are placed inside the macerationtank, separated by filter cloth; each sample is packed in a small bag of filter cloth. The mesh size used is $10 \mu \mathrm{m}$. After treatment with hydrofluoric acid the acid is drained out through a bottom-stopcock and carried along tubing directly to a waste-container for used hydrofluoric acid. The steps in the preparation techniques are described below and the procedure is discussed. 


\section{Preparation}

\section{Removal of carbonates, the macerationtank-method}

A sample is first treated in a one litre glass beaker with cold hydrochloric acid (10\%). The treatment is carried on until the reaction terminates. Violent reaction can be kept under control by adding ethanol (96\%). Finally it is heated to more than $65^{\circ} \mathrm{C}$ to dissolve magnesium carbonates. The heating period is stopped as soon as the carbonates are dissolved. Warm hydrochloric acid may damage sporopollenin walls if the heating period is longer than necessary for dissolving the carbonates.

After the dissolution of the carbonates the sample is caught on a $20 \mathrm{~cm}$ square polyester filter cloth with a mesh size of $10 \mu \mathrm{m}$. The cloth with the sample is packed as described below. The samples in the bags are then washed in water. This can be done in a domestic washing mashine. Here the bags will have a normal fine wash $\left(40^{\circ} \mathrm{C}\right)$ without washing powder or other detergents.

Small poorly-lithified, carbonate-poor samples (below 20 grams) can alternatively be treated as described below.

The sample is first crushed to $1-2 \mathrm{~mm}$ pieces. After crushing the sample is placed on a $20 \mathrm{~cm}$ square polyester filter cloth (mesh size of $10 \mu \mathrm{m}$ ). Citric acid crystals are added; since 2 grams of citric acid will dissolve 1 gram of carbonate, double the amount of the sample should be added.

The filter cloth with the sample and the citric acid crystals is loosely packed into a small bag sealed with a thick rubber band.

Each bag is then wrapped in foam rubber for protection against mechanical damage and sealed with a rubber band.

Up to about 35 samples are then treated in a domestic washing machine. The samples will have a normal boiling wash only with citric acid instead of washing powder. However, this method can only be recommended for poorly lithified, "soft" samples that are smaller than 20 grams. Larger samples will damage the filter cloth and drill cutting samples may cause damage to the filter cloth due to chemicals in the drilling mud.

\section{Removal of silicates}

About 30 to 35 samples packed in filterbags and foam rubber as described above are placed in the macerationtank between the two sieve plates (fig.1). Ten litres of cold $40 \%$ hydrofluoric acid (commercial grade) is added using connected vessels. The samples stay in the hydrofluoric acid for at least eight days. The used hydrofluoric acid is then drained out through a bottom-stopcock and conducted along tubing to a waste-acid container. After about half an hour of dripping of the hydrofluoric 
acid, the samples are washed in water, first with the shower nozzle below the cover of the macerationtank (fig. 1). After half an hour the bottom stopcock of the macerationtank is closed. Water is fed into the macerationtank through the central tube (fig. 1) and the samples are now washed by a slow waterflow from the bottom to the overflow level. After half an hour of washing in cold water, the washing process is continued with warm water. The washing process is accelerated in warm water and the samples neutralized more rapidly.

When the samples are neutral (after $2-3$ days of washing), they are given a $70^{\circ} \mathrm{C}$ wash with citric acid in the washing machine (to remove silica-fluorides) followed by a normal rinsing in the washing machine. This process will simultaneously filter the samples better than any other filtration methods.

After this treatment the samples are unpacked and washed down into a test tube. The filter pieces used for the filter bags are collected after the unpacking, washed and checked for holes. (See 3.3. for discussion of holes in the filters).

\section{Concentration of palynomorphs}

The preparation hereafter follows the conventional methods (e.g. Couper, 1958; Funkhouser \& Evitt, 1959; Schrank, 1988), with heavy liquid separation, oxidation, swirling and/or ethanol-water separation (see Hansen \& Gudmundsson, 1978), and mounting of the material in glycerol jelly.

\section{Heavy-liquid separation:}

If heavy-liquid separation is used, the separation is undertaken at a specific gravity at 2.3 at $2000 \mathrm{rpm} / \mathrm{min}$. for 20 minutes. The residue is checked for the presence of palynomorphs filled with pyrite. If too many palynomorphs are present in the residue, the residue is treated with nitric acid for 10-15 min., washed in water and reseparated in heavy liquid. This treatment of the residuum has significantly increased the number of palynomorphs recovered for many samples within the Danish region.

\section{Oxidation:}

Warning: any method of oxidation may result in violent reactions. To avoid spillage of the sample, use a large glass beaker $(250 \mathrm{ml})$.

Mild oxidation can be carried out using hydrogen peroxide. The hydrogen peroxide reacts slowly with palynomorphs. The oxidation time may be from one to several hours.

Concentrated nitric acid produces a quicker and a more immediate reaction. The sample is oxidized for a few minutes to several hours, the residue being checked regularly. The sample is washed clean with water on a acidproof filter (10 or $20 \mu \mathrm{m}$ meshes). Only when humic-clearing treatment is necessary should the sample be treated with alkalies, as these may damage the periphragm of dinoflagellate cysts 
and cause swelling of angiosperm pollen (Schrank, 1988). Ammonia water (10\%) is recommended instead of potassium hydroxide $(5 \%)$, since the latter may cause more damage to the periphragms (Schrank, 1988).

Oxidation with Schulze's solution is used on coals and other samples which need more intensive decoalification. The method is described in Couper (1958). The duration of the treatment is from about an hour to several days.

Modified ethanol-water separation:

Hansen and Gudmundsson (1978) described a method for separation of palynomorphs from samples with a high content of coal and wood particles. Y. Husfeldt and J. Jensen (Geological Survey of Denmark) modifed the method using more common laboratory equipment than the glass separation tube used by Hansen and Gudmundsson (1978).

The sample is first centrifuged and the water decanted. The sample is then suspended in ethanol ( $96 \%$ or $99 \%$ ) and left for half an hour. A round bottom flask is filled with water at room temperature, and is allowed to settle. Then the ethanol suspended sample is carefully poured onto the water in the flask, so that the water and the ethanol form two separate layers. The palynomorphs containing adsorbed ethanol will remain in the ethanol layer after 20-30 minutes whereas solid particles, such as coal fragments and minerals, will sink into the water. The miospores, dinoflagellate cysts and other microfossils are now sucked up using a pipette. The ethanol is washed out of the microfossils and the remaining part of the sample in the flask is collected on a filter (10 or $20 \mu \mathrm{m}$ meshes). Slides are made from each of the two parts of the separated sample.

Modified swirling:

Y. Husfeldt has improved the swirling method (Funkhouser and Evitt, 1959), by combining the swirling method and the ethanol-water separation technique. The sample is first suspended in ethanol for half an hour as in the ethanol-water separation method. The sample is then swirled in water as described by Funkhouser \& Evitt (1959). Hollow microfossils containing adsorbed ethanol will float more easily and are therefore more readily separated from the unwanted organic debris. The ethanol is washed out of the microfossils on a filter (10 or $20 \mu \mathrm{m}$ meshes).

\section{Ultrasonic treatment:}

Ultrasonic treatment can be used to clean microfossils and to break up larger particles of amorphous material. However if the frequency used is lower than $80.000 \mathrm{KHz}$, this treatment may damage or destroy the microfossils after only a short treatment (Caratini, 1980; Marceau, 1969). 
Filtration:

Several filtration techniques are in use at different laboratories. Some laboratories use finger-manipulation below the filter to prevent packing. This method is efficient, but involves safeguarding against acid problems etc. A method using a blowing pump was described by Neves and Dale (1963); others use the water pump for filtration under partial vacuum. This method is often combined with blowing with a small rubber-blower. However, if many samples are to be sieved, the method may cause overexertion of the arm and hand muscles. A filtration pump, which alternates between blowing and making a partial vacuum over short intervals (3-60 seconds), solves the problem. This filtration technique has improved the sieving of samples, both by being quicker and by producing cleaner residues.

At the Geological Survey of Denmark the standard filter mesh-size used in the first preparation steps is $10 \mu \mathrm{m}$. In the final steps a $180 \mu \mathrm{m}$ mesh-size may be used to separate larger organic debris from the microfossils and a $20 \mu \mathrm{m}$ mesh-size may be used in concentrating palynological samples for dinoflagellate cysts.

Mounting medium for slides:

Glycerol jelly is used as a mounting medium. The glycerol jelly recipe is that of Hill (1983). This mounting medium is found to be the least toxic medium presently available, in contrast to many other permanent mounting media containing strongly toxic organic solvents, which can be deleterious both during slide production and afterwards during microscope work and storage. It is also a mounting media with an optimal refraction index (Andersen, 1960).

The slides are not sealed. Slides dating from 1977 show no signs of damage due to drying or decomposition. We believe that the secret of long-lasting glycerol jelly slides is complete evaporation of the water before mounting.

When slides are produced, glycerol jelly and a drop of sample residue are mixed on the cover-glass and left to dry for 3 hours at $50^{\circ} \mathrm{C}$. After cooling the cover-glass is mounted on the microscope slide using glycerol jelly heated just to the melting point (approximately $50^{\circ} \mathrm{C}$ ). 


\section{Discussion of the method and tests}

Although contamination of samples prepared by the conventional methods with one sample in each test tube can occur, it is rather rare. The macerationtank-method can cause contamination of the samples if the method is not used with care. While testing the macerationtank-method, causes of contamination have been assessed. Only one cause of contamination has been found - holes in two or more filters (see below). The method has been used for about six years at the Geological Survey of Denmark.

\section{Rock types}

Many rock types have been processed and all with success.

Coals and coaly rocks only need a few grams of sample and can be processed following the normal procedure.

Claystones and siltstones require about 10-20 grams per sample although samples down to 2-3 grams will produce sufficient material for slides.

Sandstones can also be processed, but if they are almost clean quartz sandstones then larger sample sizes are needed (50-100 grams). The sample can be split into two or more separate sub-samples which are processed separately. The maximum sample size is about 50 grams in one piece of filter cloth if the washing-machine technique is used in the removal of carbonates. If the amount exceeds 50 grams the filter cloth will be damaged by the sand grains from the inside.

Chalk, limestones and dolomites can be processed with good results following the hydrochloric acid breakdown method. The amount of sample necessary varies from less than 50 grams to more than 600 grams. Due to the extensive breakdown of calcareous samples in hydrochloric acid, it is possible to process up to at least 200 grams in one piece of filter cloth.

Chert samples do not often need the first step with removal of calcareous material and can be put directly into the macerationtank. When it is required to remove calcareous matter, only the hydrochloric acid method can be used. If the sample is put into the washing machine before it is treated with hydrofluoric acid the chert pieces will cut holes in the filter cloth. The amount of sample necessary varies from about 50 grams to 100 grams.

\section{Use of washing machine}

It may seem that the use of a washing machine is a violent treatment of spores, pollen and dinoflagellate cysts but processing of samples following both the common methods and the method described here show no differences in the results. Chorate dinoflagellate cysts with delicate processes and trabeculae are undamaged regardless of which method is used. Neither do delicate spores like Kekryphalospora distincta 
Fenton \& Riley 1987 show any signs of damage which can be related to the washing machine treatment.

\section{Sources of contamination}

Crushing:

Investigating and testing the macerationtank-method revealed one outside source of contamination of samples. The use of a jaw crushing-mill did contaminate successive samples, even when cleaned carefully with brushes, wet cloths and compressed air (see below). Therefore, only easily cleaned instruments such as a hammer and anvil or an oil compression press or a swing-press are recommended.

\section{Holes in the filter cloth:}

If holes are found in the filter cloth after the preparation of a sample, then this is recorded for that sample. Under normal conditions, holes occur very rarely, in practice never being seen if the carbonates are removed from the samples using hydrochloric acid in glass beakers.

In order to determine the effect of holes on contamination, experiments with filter cloths, some without holes, some with a few small holes (about $1 \mathrm{~mm}$ in size) and some with many holes, were carried out. Each filter cloth was packed with 5 grams of sand and coloured Lycopodium spores were added. The filterbags were washed in the washing machine twice, each time they were given a normal $65^{\circ} \mathrm{C}$ wash followed by standard rinsing. After this treatment, each sample was given a heavy-liquid separation and filtered on a $10 \mu \mathrm{m}$ filter. Slides were produced and the Lycopodium spores were counted.

Table 1 shows the results. Samples from filter cloths without holes were contaminated to a minor degree. However this contamination is believed to be related to the experiment. During the experiment a very high number of spores were in the washing mashine due to the holes in the other samples; giving the possibility of spores of another colour sitting on the outside of the filterbag. These spores could have been washed off during the unpacking of the sample.

The samples with a few small holes displayed only minor contamination. The samples with large holes were almost depleted in spores and showed a high contamination.

Under normal preparation, samples are not found to be contaminated. A series of Jurassic samples were processed under normal conditions, i.e. the samples were crushed with a hammer and the carbonate removed using the washing mashine. Within this series were two different Tertiary samples known to be very rich in dinoflagellate cysts and three samples known to be barren. These samples were crushed using a jaw crushing-mill. First a barren sample was crushed in the jaw crushing-mill followed by one of the rich samples, then a barren sample followed by the second rich sample and at last the third barren sample. Between each crushing, the jaw crushing-mill was thoroughly cleaned. None of the Jurassic samples were found afterwards to contain any Tertiary dinoflagellate cysts. The first barren sample was not contaminated. 
The second barren sample and the second rich Tertiary sample were contaminated by the first Tertiary sample. The third barren sample was contaminated by both of the Tertiary samples. 


\begin{tabular}{|c|c|c|c|c|c|c|}
\hline \multirow[t]{2}{*}{ Sample } & \multicolumn{2}{|c|}{ Numbers of spores } & \multirow[t]{2}{*}{ Filter } & \multicolumn{2}{|c|}{ Counting of spores } & \multirow{2}{*}{$\begin{array}{l}\text { Spore pollution } \\
\text { in } 0 / 00\end{array}$} \\
\hline & red & green & & red & green & \\
\hline 1 & 4.702 .950 & 0 & no holes & 1419 & 3 & 2,1 \\
\hline 2 & 4.702 .950 & 0 & no holes & 1533 & 1 & 0,7 \\
\hline 3 & 0 & 4.702 .950 & no holes & 0 & 2876 & 0 \\
\hline 4 & 0 & 4.702 .950 & no holes & 2 & 1041 & 1,9 \\
\hline 5 & 0 & 4.702 .950 & no holes & 6 & 1923 & 3,1 \\
\hline 6 & 4.702 .950 & 0 & few holes & 1728 & 2 & 1,2 \\
\hline 7 & 4.702 .950 & 0 & few holes & 1651 & 5 & 3,0 \\
\hline 8 & 0 & 4.702 .950 & few holes & 4 & 1670 & 2,4 \\
\hline 9 & 0 & 4.709 .950 & few holes & 3 & 1304 & 2,3 \\
\hline 10 & 4.702 .950 & 0 & many holes & 67 & 11 & 141,0 \\
\hline 11 & 4.702 .950 & 0 & many holes & 100 & 8 & 74,1 \\
\hline 12 & 0 & 4.709 .950 & many holes & 10 & 33 & 232,6 \\
\hline 13 & 0 & 4.702 .950 & many holes & 12 & 28 & 300,0 \\
\hline
\end{tabular}

Table 1: The effect of holes in filterbags on contamination. 


\section{Conclusion}

In conclusion, the contamination of samples is primarily caused by crushing instruments like the jaw crushing-mill. The macerationtank-method is found to be as reliable as conventional methods.

(Causes of contamination of samples using any preparation method are in general to be found between careless and imprudent handling of the samples, lack of cleaning of instruments, working places, tables, beakers, etc.).

The use of the washing mashine to remove carbonates cannot be recommended for drill cutting samples or hard rocks. For these types of samples, treatment in beakers with hydrochloric acid is recommended. If one sample has a hole in the filter cloth, the sample will not be contaminated but will be sparse in organic content. If holes are present in two or more filter cloths in a series then contamination is possible. 


\section{Description of the macerationtank}

The macerationtank (Fig. 1 and 2) consists of a round container made of polypropylene. The bottom is formed as a funnel to secure the best run off. In the upper half on the front, there is a window, showing the acid- and water level.

Inside the macerationtank (fig. 1) is a piston fixed to the cover. The piston consists of two sieve plates, between which the samples are placed. The lower plate keeps the bottom drain free, the upper plate prevents the samples floating above the acid level. The sieve plates and the cover are mounted on a central tube, which also is used for conducting water to the bottom of the macerationtank. This tube is used during the washing process. Below the cover is a shower nozzle for alternative washing which is used in the beginning of the washing process.

In the top of the container there are six overflow drains, (one is shown in fig. 1) evenly spaced around the margin of the macerationtank.

In the cover, there is a tube for the inlet of hydrofluoric acid. This tube goes through the upper sieve plate giving a possibility for $\mathrm{pH}$ measurement during processing.

The container is constructed to hold about 35 samples plus 10 litres of acid. When the samples and the 10 litres of acid are in the container, there is about $8 \mathrm{~cm}$ of safety space between acid level and the overflow levels.

The cover has two security locks to fix it to the container while it is in use.

Figure 2 shows two macerationtanks placed beside each other. The distribution code on top of the macerationtank is for conducting water to either the shower nozzle or to the bottom of the macerationtank. Below each macerationtank are two stopcocks, one for outlet to the waste acid container, the other for the outlet of water to a sink.

The macerationtanks are placed on an inclined tray, which allows the water to flow from the overflows to the sink. (When the washing water is led to a sink, the general outward flow from the laboratory must go through a chemical retaining filter before it is fed into the main drain. This is of course the case at the Geological Survey of Denmark).

Also shown on figure 2 are stopcocks for water inlet (hot or cold) and water pressure regulators. These are regulated so the maximum waterflow for the washing process is gentle.

The double macerationtank is built into a standard fume cupboard. 


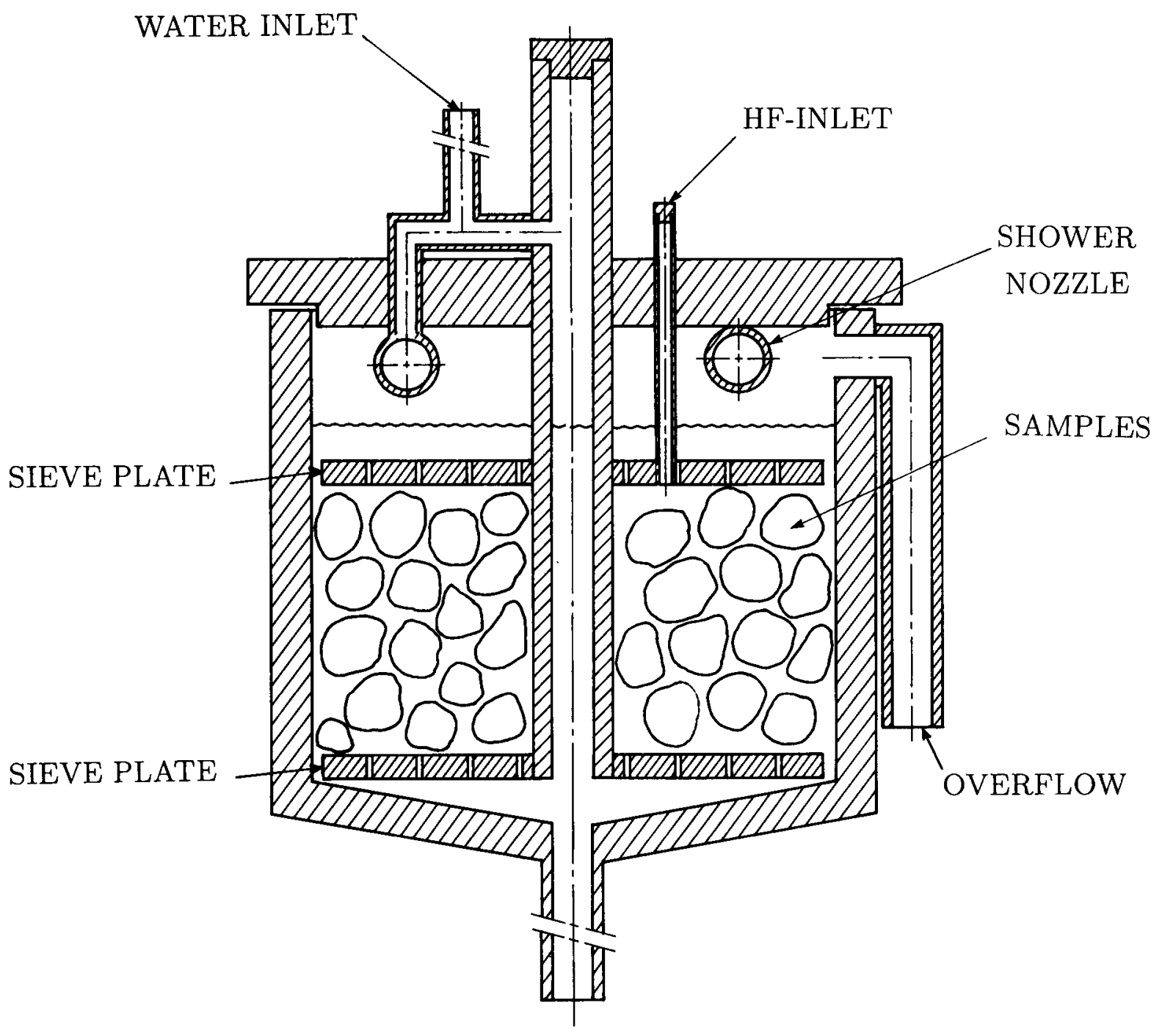

Fig. 1. Internal outline of the tank illustrating the placing of samples between the sieveplate, hydrofluoric acid inlet shower nozzle and the central tube for washing, bottom outlet and one of the overflow drains. 


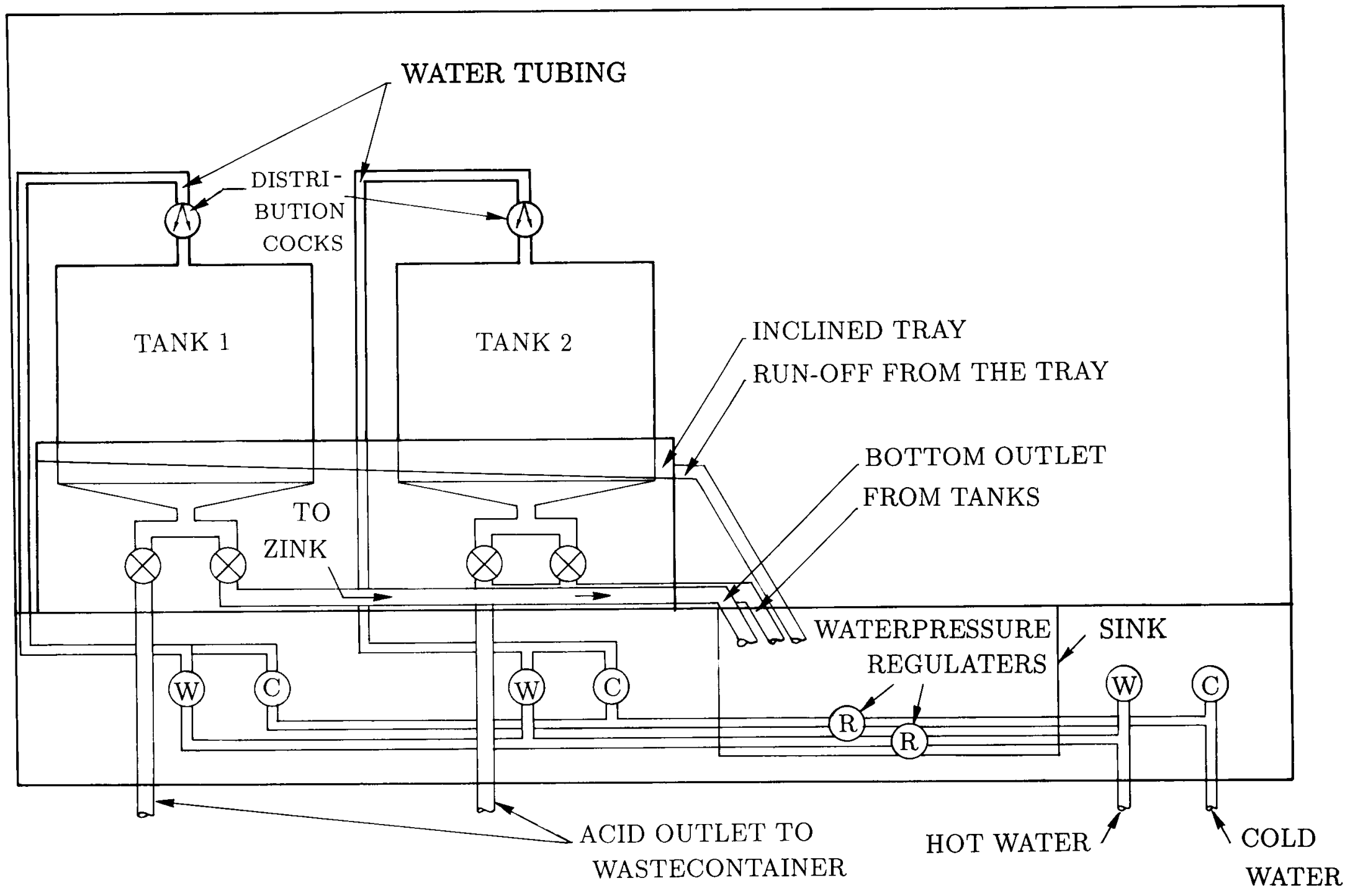




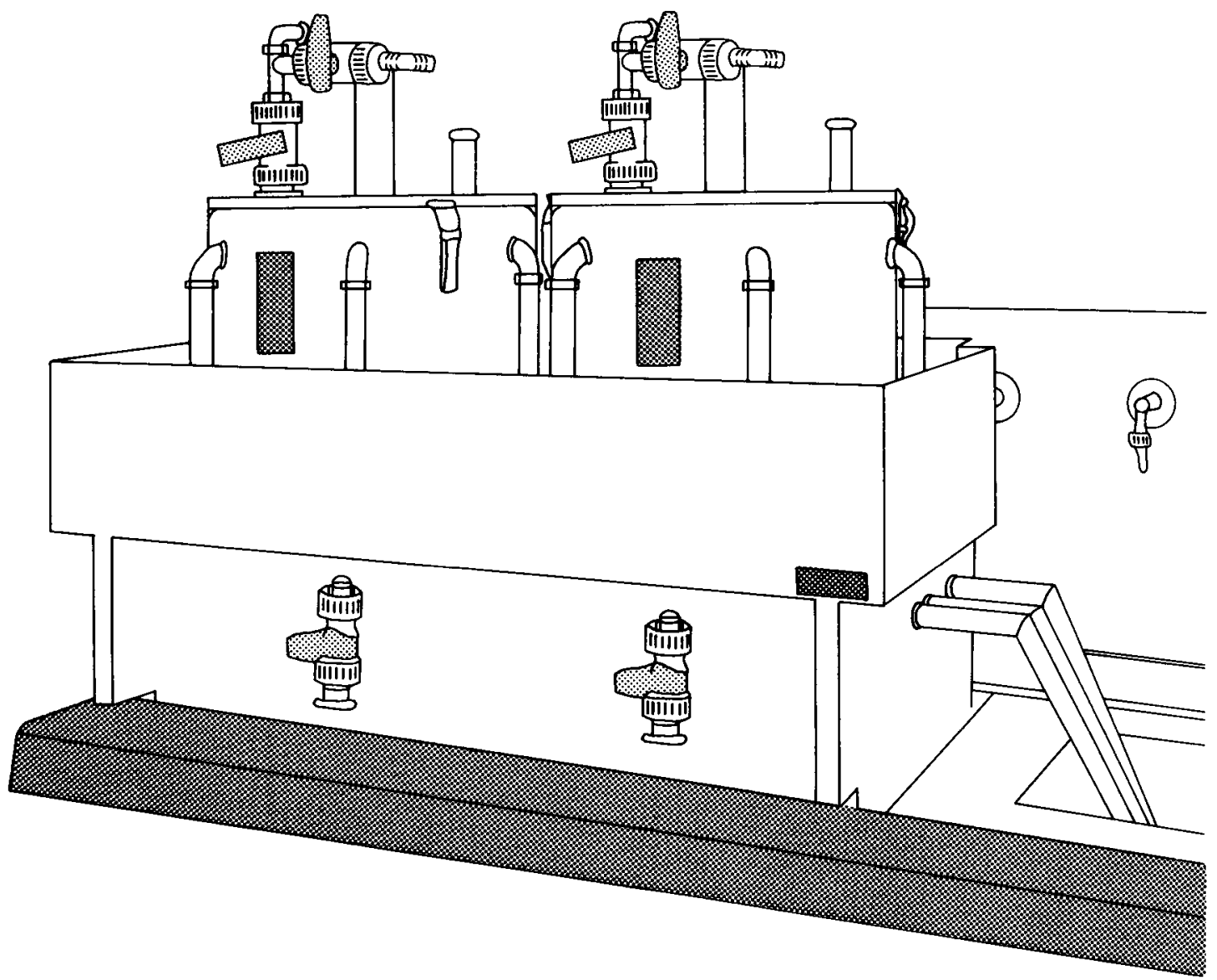

Fig. 3. Drawing of the macerationtanks in the fume cupboard. 


\section{Acknowledgements}

We are grateful to our colleagues at the Geological Survey of Denmark (DGU), who have been involved in improving palynological preparation techniques at DGU, and for their help in preparing this manuscript. Dr. B. Owens and Dr. G. Warrington, British Geological Survey, kindly read an early draft of this paper and suggested ways for its improvement.

Jens Ole Juul, JO-Plast, built the macerationtank, and S. Kaj $\phi$, Ardua, built the filtration pump. 


\section{References}

Andersen, S. T., 1960: Silicone oil as a mounting medium for pollen grains. Danmarks Geologiske Unders $\varnothing$ gelse, IV Række, 4(1), 1-24.

Caratini, C., 1980: Ultrasonic sieving to improve palynological processing of sediments: A new device. International Commision for Palynology, Newsletter, $3(1), 4$.

Couper, R.A., 1958: British Mesozoic microspores and pollen grains. A systematic and stratigraphic study. Palaeontographica, Abt. B, 103(4-6), 75-179.

Funkhouser, J.W. \& Evitt, W.R., 1959: Preparation techniques for acid insoluble microfossils. Micropaleontology 5(3), 369-375.

Gudmundsson, L., 1985: Nedsyring af uorganiske materialer ved hjælp af massenedsyringsmetoden (macerationstank-metoden). Palyno-Nytt, 2, 3-6.

Hansen, J.M. \& Gudmundsson, L., 1978: A method for separation of acid insoluble microfossils from organic debris. Micropalaeontology, 25(2), 113-117.

Hill, C.R., 1983: Preventing glycerin jelly mounts from drying out. AASP Newsletter, 16(3), 3.

Marceau, L., 1969: Effets, sur le pollen, des ultrasons de basse frequence. Pollen et Spores 11, 147-164.

Neves, R. \& Dale, B., 1963: A modified filtration system for palynological preparations. Nature 198(4882), 775-776.

Schrank, E., 1988: Effects of chemical processing on the preservation of peridinioid dinoflagellates: A case from the Late Cretaceous of the NE Africa. Review of Palaeobotany and Palynology, 56, 123-140. 
This paper deals with palynological preparation methods. A safe technique utilizing a macerationtank for hydrofluoric acid treatment of palynological samples is described. Some techniques in subsequent preparation are mentioned.

Ministry of the Environment

Geological Survey of Denmark

Thoravej 8

DK 2400 Copenhagen NV

Denmark

Phone +4531106600

ISBN 87-88640-57-4

Fax +4531196868 